\title{
Agarwood Oil Quality Classification based on Aromatic Alkane using Portable FTIR Spectroscopy Technique
}

\author{
Hasnida Saad $^{1 *}$, Nur Irdiena Balqis Nor Azmi ${ }^{1}$, Husna Abdul Rahman ${ }^{1}$, Rafidah Rosman ${ }^{1}$, \\ Maizatul Zolkapli ${ }^{1}$ \\ ${ }^{1}$ Faculty of Electrical Engineering, Universiti Teknologi MARA (UiTM), Selangor, Malaysia, \\ *hasnidasaad@uitm.edu.my
}

\begin{abstract}
This study classifies the quality of local Agarwood oil based on the absorbance intensity of aromatic alkane (pleasant odors), which is represented by the $\mathrm{C}-\mathrm{H}$ bond. Agarwood is a valuable tree species because of its widely used as perfumes and in traditional and religious ceremonies. In this research article, the absorbance intensity of the $\mathrm{C}-\mathrm{H}$ bond was carried out using Cary 630 FTIR spectrometer. In this research article, the quality of Agarwood oil was successfully graded based on the absorbance intensity of the $\mathrm{C}-\mathrm{H}$ bond measured at $3417.68 \mathrm{~nm}$ wavelength.
\end{abstract}

Key words: aromatic alkanes, agarwood oil, Cary 630 FTIR spectrometer, absorbance intensity, $\mathrm{C}-\mathrm{H}$ bond

\section{INTRODUCTION}

Agarwood trees or its scientific name, Aquilaria Malaccensis can be found in South East Asia such as Malaysia, Indonesia, Cambodia, Myanmar, Vietnam, Indonesia, and China [1]. It is a non-timber forest product which has been spiked up around the world due to its widely used as perfumes, and in traditional and religious ceremony[2][3].

The main ingredients in agarwood from different areas were sesquiterpenoids, aromatic species, and chromone compounds [4][5][6]. Before the Agarwood tree is processed into oil, it must be extracted and went through some analyzing process to sort out the quality. The chemical composition of agarwood has been studied extensively in [4][5][9]. The chemical compound found in Agarwood oil is different when a different extraction method and analyzing method is applied. Different types of Agarwood also produced different chemical compounds even though the same extraction method and analysing method used [4][9].

Agarwood oil can be extracted using Hydrodistillation (HD), supercritical fluid extraction (SFE), Headspace-Solid Phase Microextraction (HS-SPME) with fiber coating [5], [7]-[9] and Polydimethylsiloxane (PMDS) extraction method [10]. However, hydrodistillation is the most used method for extraction. This is because other extraction methods operated at a high temperature which can destroy the originality of the Agarwood oil. Therefore, hydrodistillation is preferred even though it consumes a lot of time [10].

Traditionally, Agarwood oil was graded by hiring a human expert to classify their oil quality. However, studies show that it has questionable accuracy because the human nose has limitation because which easier to get fatigued when used to smell for a long period and exposed to a high volume of a sample [1]. Nowadays, Gas chromatography flame-ionization detector (GC-FID) and gas chromatography-mass spectrometer (GC-MS) are the common methods applied to analyze an Agarwood oil [5], [7]-[9]. Even though GC techniques are the most reliable methods, but analysis cannot be carried out in situ because GC was not portable [11][12].

The volatile components and effective constituents found in Agarwood oil were phenylethyl chromone $\left(\mathrm{C}_{17} \mathrm{H}_{15} \mathrm{O}_{3}\right)$, Agarospirol $\left(\mathrm{C}_{15} \mathrm{H}_{26} \mathrm{O}\right), \beta$-Guaiene $\left(\mathrm{C}_{15} \mathrm{H}_{24}\right)$, Benxylacatone $\left(\mathrm{C}_{10} \mathrm{H}_{12} \mathrm{O}\right)$, and 2-(2phenylethyl)chromone $\left(\mathrm{C}_{17} \mathrm{H}_{14} \mathrm{O}_{2}\right)$ [13]. In the chemical analysis, four major compounds were detected by Fourier Transform Infrared Spectroscopy (FTIR) which were C-H bond (aromatic alkane), C-C stretching (aromatic alkane), C-O stretching (ether), and $\mathrm{C}-\mathrm{H}$ bond (aromatic ring) [14][15][16]. This functional group is important in identifying the characteristic of Agarwood oil. Figure 1 shows the infrared spectrum region where these chemical functional groups can be found.

\begin{tabular}{|c|c|c|c|c|}
\hline \multirow{2}{*}{$\begin{array}{l}\text { Group band range } \\
\left(\mathrm{cm}^{-1}\right)\end{array}$} & \multirow[t]{2}{*}{ Bond } & \multirow[t]{2}{*}{ Functional Group } & \multicolumn{2}{|c|}{ Wavenumber $\left(\mathrm{cm}^{-1}\right)$} \\
\hline & & & $\begin{array}{c}\text { Without } \\
\text { Inoculation }\end{array}$ & With Inoculation \\
\hline $3600=3400$ & $\mathrm{O}-\mathrm{H}$ bond & Alcohol & $\cdot$ & $=$ \\
\hline $3400-3300$ & $\mathrm{O}-\mathrm{H}$ bond & Water & - & - \\
\hline $3000-2800$ & C-H bond & Aromatic Alkane & 2925,2853 & 2916,2849 \\
\hline $1710-1665$ & $\mathrm{C}=0$ stretching & a, $\beta$-unsaturated aldehydes, ketones & 1709 & 1701 \\
\hline $1640-1630$ & $\mathrm{H}-\mathrm{O}-\mathrm{H}$ bond & Water & - & - \\
\hline $1500-1400$ & C-C stretching & Aromatic Alkane & 1455 & 1464 \\
\hline $1380-1350$ & $\begin{array}{c}\mathrm{C}-\mathrm{H} \text { bending vibration } \\
\text {-OCOCH }\end{array}$ & Alkane & 1378 & 1378 \\
\hline $1275-1180$ & C-O stretching & Ether & 1214 & 1187 \\
\hline $900-690$ & $\mathrm{C}$-H bond & Aromatic Ring & 891 & 857 \\
\hline
\end{tabular}

Figure 1: Agarwood Chemical Functional Group [14][15][16].

In this research work, the mid-infrared region was utilized to identify the C-H bond (aromatic alkane) of Agarwood oil. The classification of Agarwood oil was determined based on the absorbance intensity of the $\mathrm{C}-\mathrm{H}$ bond. The measurement was conducted using Agilent Cary 630 FTIR Spectrometer [17]. This measurement technique is related to a study of the interaction between the electromagnetic radiation and the matters in the infrared region [18][19].

Figure 2 shows the FTIR spectrometer which is operated from $2500 \mathrm{~nm}-15500 \mathrm{~nm}$ wavelength. This spectrometer is portable and able to conduct measurement in situ. It has a probe which can move vertically to clamp semi-solid or solid 
sample and having an electrical port to connect to a computer for data processing.

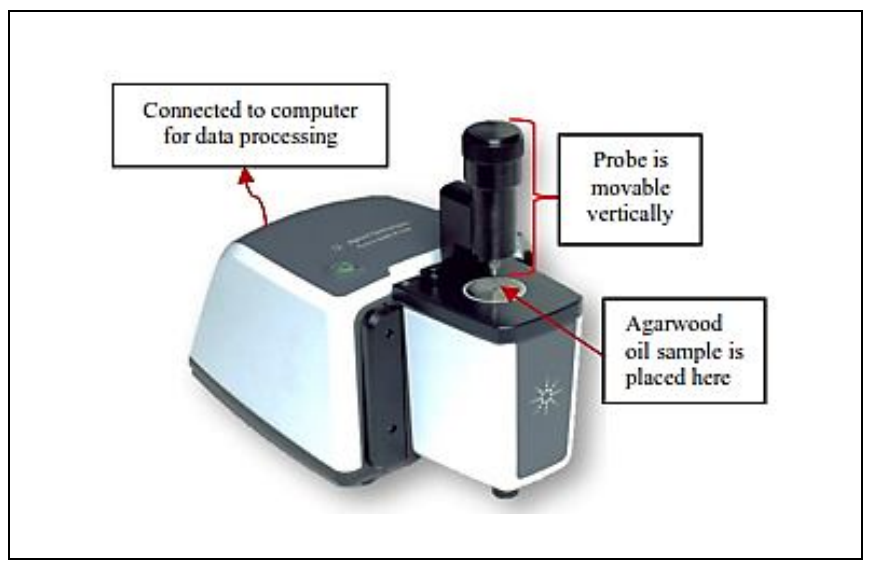

Figure 2: Cary 630 FTIR Spectrometer [17]

The principle of the FTIR spectrometer is based on the Beer-Lambert law. The law relates the absorbance intensity to the concentration of the materials where the light is travelling. Beer's Lambert Law can be written as:

$$
\begin{aligned}
& \begin{array}{l}
\mathrm{A}=\varepsilon c l \\
\text { where }
\end{array} \\
& \begin{array}{l}
\mathrm{A}=\text { Absorbance }(\mathrm{AU}) \\
\varepsilon=\text { Absorptivity }\left(\mathrm{mol}^{-1} \mathrm{~cm}^{-1}\right) \\
c=\text { Analyte concentration }(\mathrm{mol}) \\
l=\text { Length of solution the light passes through }(\mathrm{cm})
\end{array}
\end{aligned}
$$

Therefore, the absorbance intensity is directly proportional to the concentration of the chemical constituents in a sample solution [20].

\section{METHOD}

In this experiment, seven samples of Agarwood essential oils were examined. Each of the oil samples was named as K1, K2, K3, K4, K5, K6, and K7. Figure 3 shows the labelled Agarwood oil samples. The sample of the Agarwood oil used is in this experiment was purchased from local Agarwood farmers.

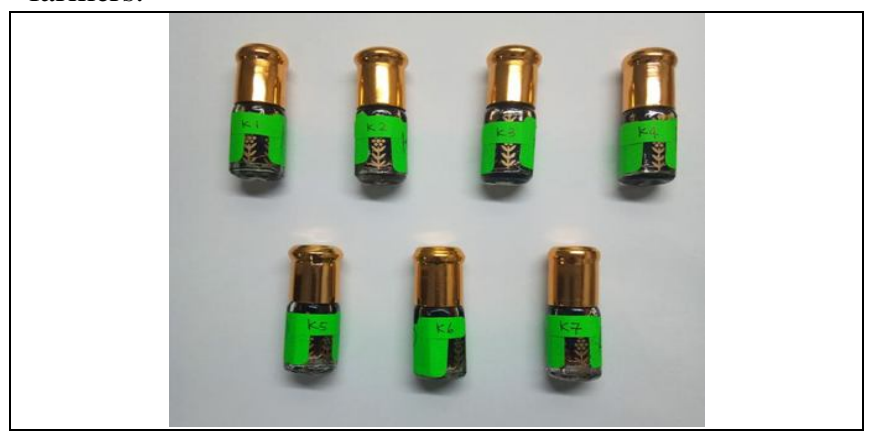

Figure 3: Agarwood oil samples
The first step in experimental work was cleaning the platform of the spectrometer thoroughly before putting the Agarwood oil sample on the platform. This action will ensure no interference from the other substances. Then, the spectrometer must be warming up for about 10 minutes before taking any measurement. This will ensure, the intensity of light travelling into the Agarwood oil sample is optimized and stabilized. Hence, the obtained result will be much accurate.

After warming up the spectrometer for 10 minutes, the background solution for agarwood oil should be placed on the spectrometer platform. Background solution is usually a solvent used to dilute the Agarwood oil. The determination of background solution is important because the researcher will obtain the measurement result without the solvent of the Agarwood oil. If the dilution is unknown, the air background should be selected. For this Agarwood oil sample, the air background was chosen because the solvent is unknown. After selecting the background solution, a small droplet of Agarwood oil was placed on the platform of the spectrometer as shown in Figure 2. Each of the oil samples will be scanned by the infrared light three times to get a consistent result. Before placing the next sample, the platform must be cleaned up again.

For data processing, the Cary 630 FTIR spectrometer was connected to a computer installed with specific data acquisition software which can determine the chemical content of Agarwood oil. The output features for each Agarwood oil sample is represented by the optical spectrum of absorbance intensity (AU) versus the range of the scanned infrared wavelength in nanometer $(\mathrm{nm})$. With the help of a build-in chemical database in our data acquisition software, the absorbance wavelength of carbon-hydrogen $(\mathrm{C}-\mathrm{H})$ bonds can be identified easily.

\section{RESULTS AND DISCUSSIONS}

The absorbance spectra for seven samples of Agarwood oil are presented in Figure 4(a) to Figure 4(g). Only the absorbance signal from $2800 \mathrm{~nm}$ to $14800 \mathrm{~nm}$ wavelength was considered for analysis. This is because there is a lot of noise outside this wavelength range.

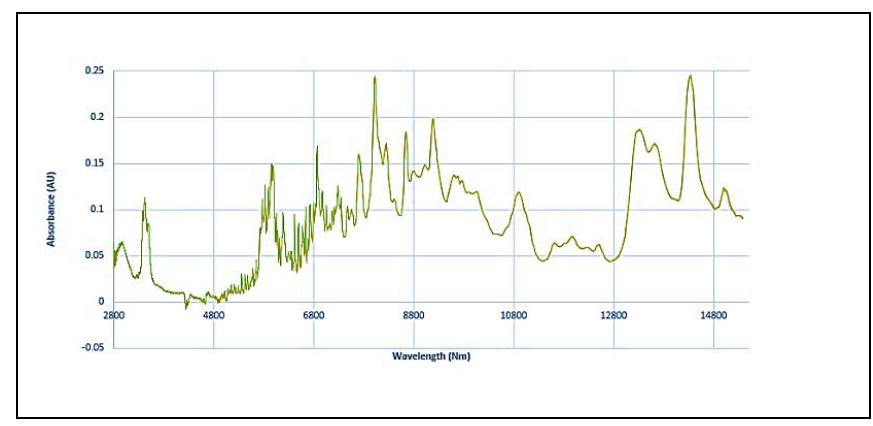

Figure 4(a): The Absorbance Spectra of Sample K1 
Hasnida Saad et al., International Journal of Emerging Trends in Engineering Research, 8(10), October 2020, 6969 - 6973

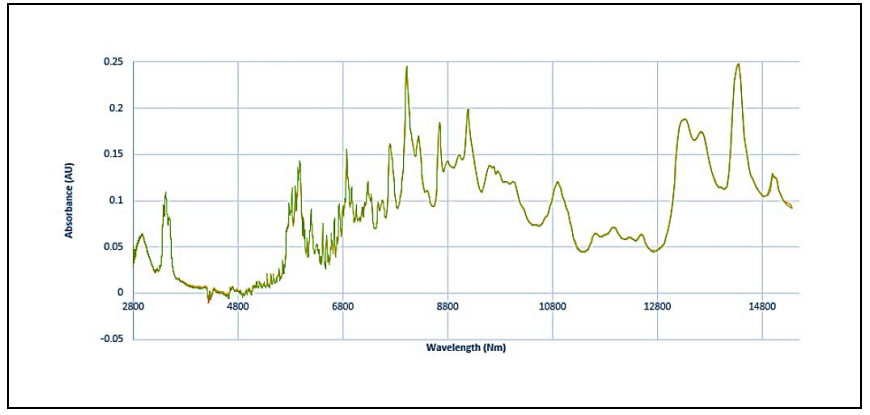

Figure 4(b): The Absorbance Spectra of Sample K2

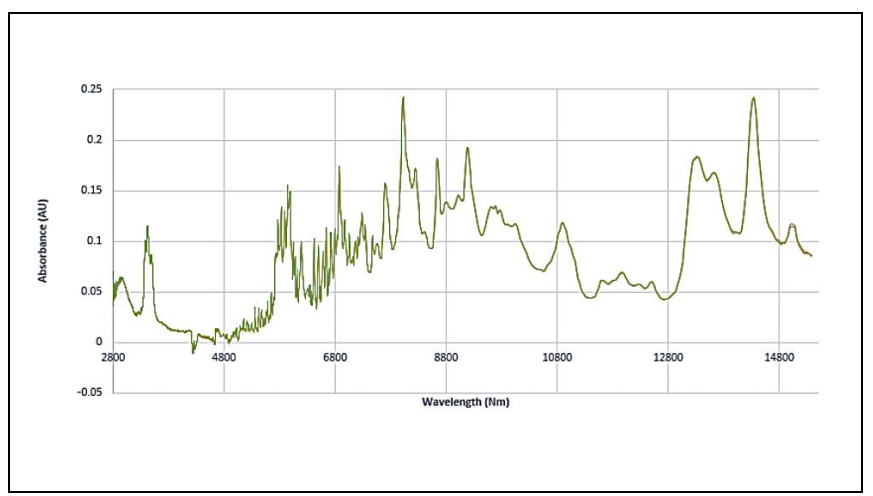

Figure 4(c): The Absorbance Spectra of Sample K3

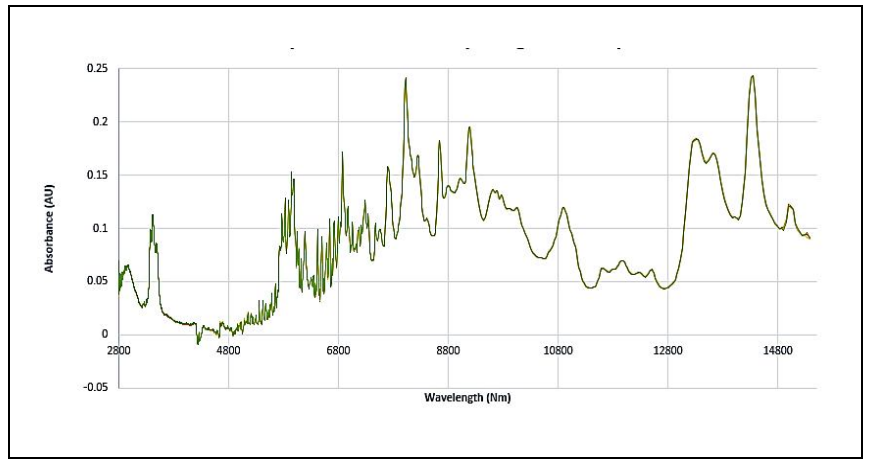

Figure 4(d): The Absorbance Spectra of Sample K4

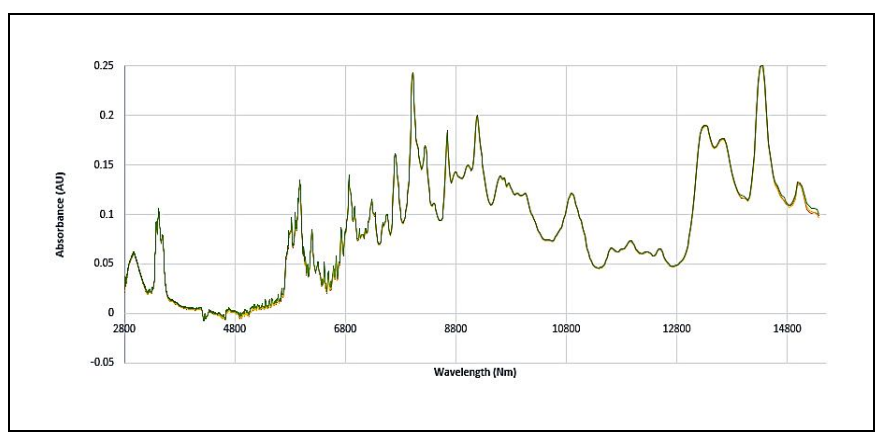

Figure 4(e): The Absorbance Spectra of Sample K5

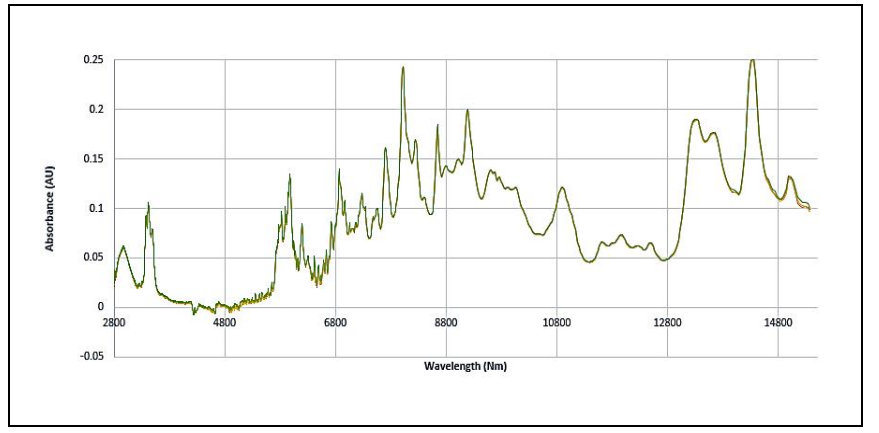

Figure 4(f): The Absorbance Spectra of Sample K6

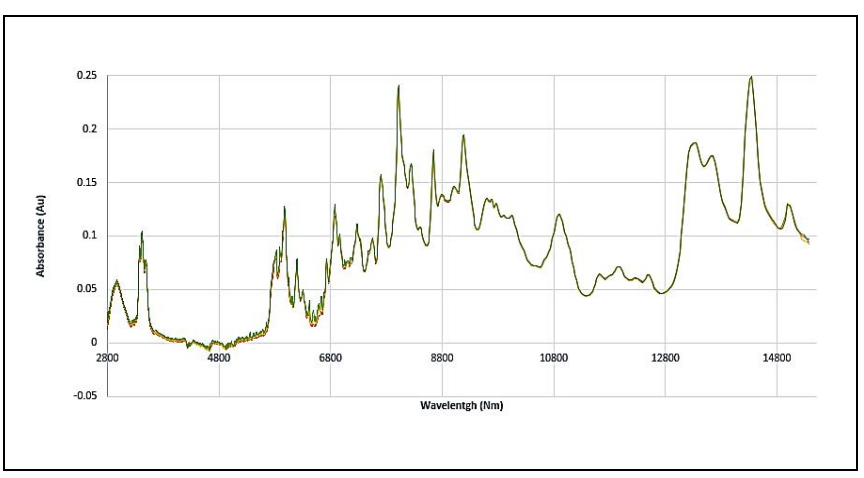

Figure 4(g): The Absorbance Spectra of Sample K7

Based on Beer's Lambert law, absorbance can have a value from zero to one. If absorbance is zero, it means that the solution is transparent or clear as the light can pass through the solution or there is no light has been absorbed. If the absorbance is measured at one, it means that no light passes through the solution. Based on these results, the Agarwood oil has absorbed some of the infrared lights.

For comparison, the absorbance spectrum for each Agarwood oil sample was mapped in the same spectrum as in Figure 5.

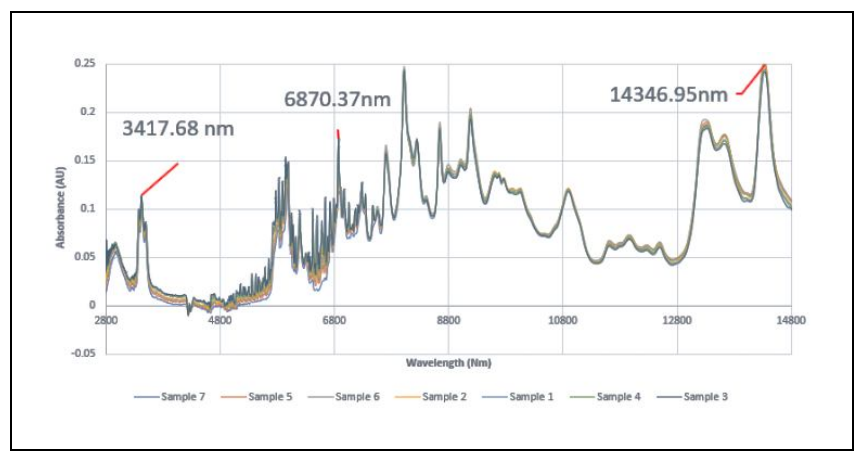

Figure 5: The absorbance spectrum of seven Agarwood oil samples within $2800 \mathrm{~nm}-14800 \mathrm{~nm}$ wavelength

In Figure 5, several absorbance peaks can be observed from $2800 \mathrm{~nm}$ to $14800 \mathrm{~nm}$ wavelength. However, three different significant peaks are significant for analysis. As shown in the 
figure, wavelength $3417.68 \mathrm{~nm}$ represents the $\mathrm{C}-\mathrm{H}$ bond of aromatic alkane, meanwhile, at a wavelength of $6870.37 \mathrm{~nm}$, the peak represents the $\mathrm{C}-\mathrm{C}$ bonds. The third significant peak at $14346.95 \mathrm{~nm}$ wavelength represents the $\mathrm{C}-\mathrm{H}$ bond of the aromatic ring [14][15][16].

In this research work, the classification of Agarwood oil quality is based on the intensity of the aromatic alkane $\mathrm{C}-\mathrm{H}$ bond presents in the sample. Therefore, the absorbance spectrum of Agarwood oil is focusing on $3200 \mathrm{~nm}$ to $3700 \mathrm{~nm}$ wavelength as in Figure 6.

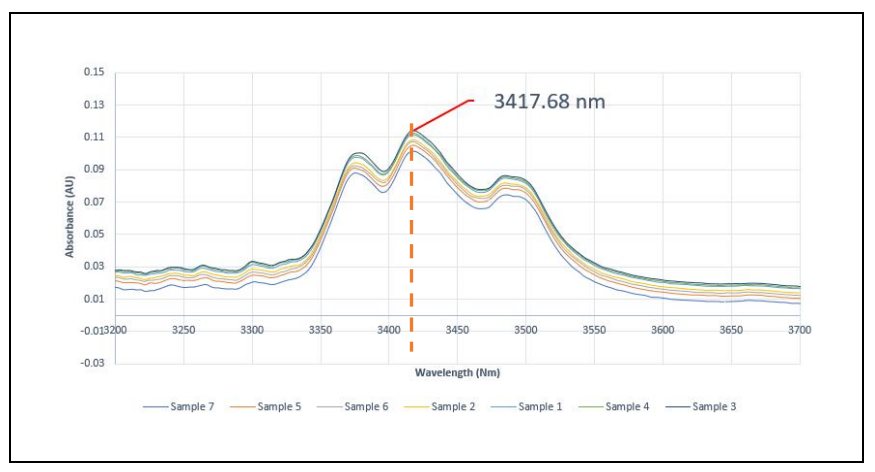

Figure 6: The absorbance spectra of seven Agarwood oil samples within $3200 \mathrm{~nm}-3700 \mathrm{~nm}$ wavelength

Based on the absorbance spectrum in Figure 6, the value of the absorbance intensity of Agarwood Oils is tabulated in Table 1. The absorbance intensity of Agarwood oil samples is listed in ascending order.

Table 1: Absorbance intensity of Agarwood Oil

\begin{tabular}{|c|c|}
\hline $\begin{array}{c}\text { Absorbance } \\
\text { Intensity (AU) }\end{array}$ & $\begin{array}{c}\text { Agarwood Oil } \\
\text { Sample }\end{array}$ \\
\hline 0.1015 & $\mathrm{~K} 7$ \\
\hline 0.1052 & $\mathrm{~K} 5$ \\
\hline 0.1074 & $\mathrm{~K} 6$ \\
\hline 0.1084 & $\mathrm{~K} 2$ \\
\hline 0.11178 & $\mathrm{~K} 1$ \\
\hline 0.11273 & $\mathrm{~K} 4$ \\
\hline 0.11423 & $\mathrm{~K} 3$ \\
\hline
\end{tabular}

From Table 1, each of the Agarwood Oil samples has a different intensity of C-H bonds. Sample K3 has the highest absorbance intensity as compared to others. A high absorbance value has resulted from a high concentration of $\mathrm{C}-\mathrm{H}$ bonds that have interacted with the infrared lights. This explains that more infrared lights are absorbed by the sample K3. More lights are absorbed because more energy is needed to interact and vibrate the $\mathrm{C}-\mathrm{H}$ bonds in Agarwood oil as compared to the other samples. In contrast, if the sample has a lower content of the $\mathrm{C}-\mathrm{H}$ bond, the absorbance intensity becomes lower as well.

The quality of agarwood oil can be sorted based on the absorbance intensity of the $\mathrm{C}-\mathrm{H}$ bond of aromatic alkane presented in the sample. The ranking of oil quality is tabulated in Table 2.
Table 2: Grading the quality of Agarwood Oil based on absorbance intensity of $\mathrm{C}-\mathrm{H}$ bond (aromatic alkane)

\begin{tabular}{|c|c|c|c|}
\hline $\begin{array}{c}\text { Absorbance } \\
\text { Intensity (AU) }\end{array}$ & $\begin{array}{c}\text { Agarwood Oil } \\
\text { Sample }\end{array}$ & $\begin{array}{c}\text { Ranking of Oil } \\
\text { Quality }\end{array}$ \\
\hline 0.11423 & $\mathrm{~K} 3$ & 1 (Highest) & \\
\hline 0.11273 & $\mathrm{~K} 4$ & 2 & \\
\hline 0.11178 & $\mathrm{~K} 1$ & 3 & \\
\hline 0.1084 & $\mathrm{~K} 2$ & 4 & \\
\hline 0.1074 & $\mathrm{~K} 6$ & 5 & \\
\hline 0.1052 & $\mathrm{~K} 5$ & 6 & $\checkmark$ \\
\hline 0.1015 & $\mathrm{~K} 7$ & 7 (Lowest) \\
\hline
\end{tabular}

\section{CONCLUSION}

The agarwood oil quality is successfully examined based on the absorbance intensity of the $\mathrm{C}-\mathrm{H}$ bond measured at $3417.68 \mathrm{~nm}$ wavelength using Cary 630 FTIR Spectrometer. The intensity of the $\mathrm{C}-\mathrm{H}$ bond also represents an aromatic alkane or pleasant odors of Agarwood oil. The finding is significant especially for in-situ Agarwood oil quality grading and its related research area.

\section{ACKNOWLEDGEMENT}

This research is funded by Research Management Centre, Universiti Teknologi MARA (UiTM) Selangor, Malaysia. The authors would like to thank Ir. Ts. Dr. Nurlaila Ismail for her valuable knowledge contribution to this article.

\section{REFERENCES}

[1] M. A. H. Abas, N. Ismail, N. A. Ali, S. Tajuddin, and N. M. Tahir, "Agarwood oil quality classification using support vector classifier and grid search cross validation hyperparameter tuning," Int. J. Emerg. Trends Eng. Res., vol. 8, no. 6, pp. 2551-2556, 2020, doi: 10.30534/ijeter/2020/55862020.

[2] A. Zuhaidi, "Growth Performance of Eight Years Old Aquilaria malaccensis: Some Management Considerations," pp. 75-78, 2018.

[3] S. Policy et al., "What Is Agarwood," pp. 1-5, 2019.

[4] T. O. P. Posts, A. Us, C. Us, A. Researches, B. Posts, and O. U. D. Oil, "Agarwood oil Chemical compositions," pp. 1-7, 2019.

[5] Y. Z. H.-Y. Hashim, N. I. Ismail, and P. Abbas, "Analysis of Chemical Compounds of Agarwood Oil From Different Species By Gas Chromatography Mass Spectrometry (Gcms)," IIUM Eng. J., vol. 15, no. 1, pp. 55-60, 2014, doi: 10.31436/iiumej.v15i1.469.

[6] M. H. Haron, M. N. Taib, N. Ismail, N. Azahmohdali, and S. N. Tajuddin, "Grading of agarwood oil quality based on its chemical compounds using self organizing map (SOM)," Int. J. Emerg. Trends Eng. Res., vol. 8, no. 7, pp. 3728-3736, 2020, doi: 10.30534/ijeter/2020/135872020.

[7] B. P. Brugger, "Identification of Chemical Constituents of Agarwood (Aquilaria Malaccencis) 
Oil Extracted by Supercritical Fluid and Hydrodistillation Method," no. April, 2014.

[8] C. H. Hung, C. Y. Lee, C. L. Yang, and M. R. Lee, "Classification and differentiation of agarwoods by using non-targeted HS-SPME-GC/MS and multivariate analysis," Anal. Methods, vol. 6, no. 18, pp. 7449-7456, 2014, doi: 10.1039/c4ay01151a.

[9] D. T. Ahmaed, "Investigation of Agarwood Compounds in Aquilaria malaccensis \& Aquilaria Rostrata Chipwood by Using Solid Phase Microextraction," Biomed. J. Sci. Tech. Res., vol. 1, no. $6, \quad$ pp. 1-8, 2017, doi: 10.26717/bjstr.2017.01.000499.

[10] G. Health and C. Editorial, "9 Powerful Bene ๑ ?ts Of Agarwood Oil You Should Know About," pp. 1-4, 2019.

[11] B. Kuswandi, T. Irmawati, M. A. Hidayat, Jayus, and M. Ahmad, "A simple visual ethanol biosensor based on alcohol oxidase immobilized onto polyaniline film for halal verification of fermented beverage samples.," Sensors (Basel)., vol. 14, no. 2, pp. 2135-49, Jan. 2014, doi: 10.3390/s140202135.

[12] M. Wang, Y. Choong, N. Su, and M. Lee, "A Rapid Method for Determination of Ethanol in Alcoholic Beverages Using Capillary Gas Chromatography," J. food Drug Anal., vol. 11, no. 2, pp. 133-140, 2003.

[13] M. R. Wang, W. Li, S. Luo, X. Zhao, C. H. Ma, and S. $\mathrm{X}$. Liu, "GC-MS study of the chemical components of different aquilaria sinensis (lour.) gilgorgans and agarwood from different asian countries," Molecules, vol. 23, no. 9, 2018, doi: 10.3390/molecules23092168.

[14] N. R. M. Nasardin et al., "Comparison of chemical compounds of essential oils from natural agarwood and inoculated agarwood (Roselle-based inoculation)," Indones. J. Electr. Eng. Comput. Sci., vol. 11, no. 2, pp. 677-681, 2018, doi: 10.11591/ijeecs.v11.i2.pp677-681.

[15] M. T. S. Syaima, F. Adam, A. S. M. Nizam, M. Z. Y. Farah, and S. M. S. Saufi, "Molecular nano-sieve approach by the application of polypiperazine (PPA) based membrane for the recovery of water soluble agarwood (Aquilarria Malaccensis) marker molecules," ARPN J. Eng. Appl. Sci., vol. 11, no. 4, pp. 2174-2178, 2016.

[16] N. F. Jamahseri, M. N. M. Rodhi, N. H. Zulkarnain, N. C. Husain, and A. F. S. Masruddin, "FTIR analysis of phenolic compound as pancreatic lipase inhibitor from inoculated Aquilaria malaccensis," Malaysian J. Anal. Sci., vol. 18, no. 3, pp. 683-689, 2014.

[17] H. A. R. Hasnida Saad, Maizatul Zolkapli, "Quantification analysis of ethanol mixtures using cary 630 FTIR spectrometer," 2019.

[18] Y. B. C. M. S. Z. A. A. Rahman, "Fourier Transform Infrared (FTIR) Spectroscopy: Development, Techniques, and Application in the Analyses of Fats and Oils," in Fourier Transform Infrared Spectroscopy, 2010, pp. 1-26.

[19] S. Corsetti, D. McGloin, and J. Kiefer, "Comparison of Raman and IR spectroscopy for quantitative analysis of gasoline/ethanol blends," Fuel, vol. 166, pp. 488-494, Feb. 2016, doi: 10.1016/j.fuel.2015.11.018.

[20] S. L. Upstone, "Ultraviolet / Visible Light Absorption Spectrophotometry in Clinical Chemistry," Encyclopedia of Analytical Chemistry. John Wiley \& Sons, Inc., pp. 1699-1714, 2000. 